\title{
Nano-titania-supported Preyssler-type heteropolyacid: An efficient and reusable catalyst in ultrasound-promoted synthesis of $4 H$-chromenes and $4 H$-pyrano[2,3-c]pyrazoles
}

\author{
DAVOOD AZARIFAR*, SEYED-MOLA KHATAMI and RAZIEH NEJAT-YAMI \\ Faculty of Chemistry, Bu-Ali Sina University, 65178, Hamedan, Iran \\ e-mail: azarifardavood@gmail.com
}

MS received 21 July 2013; revised 30 September 2013; accepted 9 October 2013

\begin{abstract}
An efficient and convenient procedure has been described for one-pot multi-component synthesis of tetrahydrobenzo[b]pyrans known as $4 H$-chromenes and 1,4-dihydropyrano[2,3-c]pyrazole derivatives in the presence of nano-titania-supported Preyssler-type heteropolyacid, n- $\mathrm{TiO}_{2} / \mathrm{H}_{14}\left[\mathrm{NaP}_{5} \mathrm{~W}_{30} \mathrm{O}_{110}\right]$, as a heterogeneous catalyst. The reactions proceeded smoothly under ultrasound irradiation condition to afford the corresponding products in quantitative yields. The catalyst can be easily recovered and reused for several successive fresh runs with no significant loss of catalytic activity.
\end{abstract}

Keywords. Preyssler-type heteropolyacid; nano-titania; $4 H$-chromene; $4 H$-pyrano[2,3-c]pyrazole; multicomponent reaction; ultrasound irradiation.

\section{Introduction}

Multi-component coupling reactions (MCRs) are known as efficient procedures for generating various products in organic and medical chemistry, and have attracted much industrial and academic interests. ${ }^{1,2}$ Moreover, these reactions appear as useful sources for approaching small drug-like molecules with several levels of structural diversity. ${ }^{3}$ In such processes, three or more compounds undergo consecutive reactions in a single event to form new products, which contain the essential parts of all the starting materials.

Pyrans belong to an important class of heterocyclic compounds which exhibit wide range of biological activities, ${ }^{4}$ and are widely employed as cosmetics, pigments and potentially biodegradable agrochemicals. ${ }^{5}$ In recent years, various methods have emerged from the literature for the synthesis of these compounds. Most of these methods employ various catalysts such as ionic liquids, ${ }^{6}$ hexadecyltrimethyl ammonium bromide, ${ }^{7} \mathrm{Mg} / \mathrm{La}$ mixed metal oxides, ${ }^{8}$ and nano-silica ${ }^{9}$ under different conditions including the use of reactants in solid or molten state, ${ }^{10}$ and electrolysis condition. ${ }^{11}$

In addition, pyrano[2,3-c]pyrazoles constitute important precursors to promising drugs in the field of medicinal chemistry and exhibit wide range of bio-

*For correspondence logical activities. ${ }^{12-14}$ Hence, development of new synthetic strategies in this field using easily accessible and benign catalysts appears to be an interesting challenge. The most used methods for the synthesis of pyrano[2, 3 -c]pyrazoles involve three-component cyclocondensation of 3-methyl-1-phenylpyrazolin-5-one with aldehydes and malononitrile, that benefits the use of ionic liquids, ${ }^{15}$ refluxing in water, ${ }^{16,17}$ or using piperidine, ${ }^{18}$ cupreine, ${ }^{19}$ and $\mathrm{MgO}^{20}$ as catalysts. However, many of these methods suffer from certain drawbacks such as low yield, harsh reaction conditions, prolonged reaction time, and application of hazardous and/or costly catalysts and solvents. Therefore, development of greener, clean, and environmentally friendly approaches is still in demand. Moreover, application of ultrasound irradiation in so-called 'sonochemistry' has received enormous attention since it offers a versatile and challenging technique in organic synthesis. Ultrasonic irradiation technique has been employed not only to decrease reaction times but also to improve yields in a large variety of organic syntheses. ${ }^{21-23}$

Currently, metal-oxide nano-particles as versatile heterogeneous catalysts have offered a new and environmentally benign approach towards modern synthetic organic chemistry. ${ }^{24-27}$ Recently, we have reported the use of nano-magnetic complex lanthanum strontium magnesium oxide as an efficient catalyst in ultrasoundaccelerated synthesis of the titled compounds. ${ }^{28}$

It has been known that the supported or bulktype Preyssler-type heteropolyacid can exhibit high 


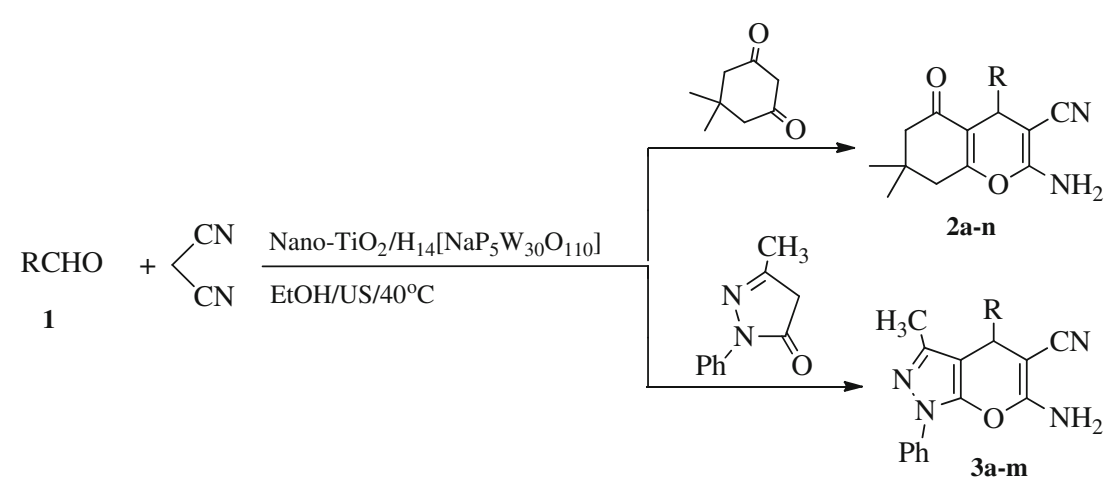

Scheme 1. Ultrasound-accelerated synthesis of $4 H$-chromenes and dihydropyrano [2,3-c] pyrazoles catalysed by nano- $\mathrm{TiO}_{2} / \mathrm{H}_{14}\left[\mathrm{NaP}_{5} \mathrm{~W}_{30} \mathrm{O}_{110}\right]$.

catalytic activity in various organic reactions. ${ }^{29,30}$ In this regard, nano-titania-supported Preyssler-type heteropolyacid has been explored as highly efficient solid acid catalyst which effects various chemoselective reactions in liquid media. ${ }^{31,32}$

With regard to the importance of tetrahydrobenzo[b]pyrans ( $4 H$-chromenes) and pyrano[2,3-c]pyrazoles in synthetic organic chemistry, herein, we wish to report the one-pot three-component synthesis of highly functionalized $4 H$-chromenes $\mathbf{2 a}-\mathbf{k}$ and $4 H$-pyrano[2,3-c]pyrazoles 3a-l from the ultrasoundpromoted reactions between aldehydes $\mathbf{1}$, malononitrile and 5,5-dimethylcyclohexan-1,3-dione (dimedone) or 3-methyl-1-phenyl-2-pyrazolin-5-one, respectively, in the presence of nano-titania-supported Preyssler-type heteropolyacid as an efficient and reusable heterogeneous catalyst in $\mathrm{EtOH}$ at $40^{\circ} \mathrm{C}$ (scheme 1).

\section{Experimental}

\subsection{Materials and instruments}

All the chemicals used in this research including the commercially available micro-titania were purchased from Merck Chemical Company and used without purification. Titanium tetra $n$-butoxide (TTB) obtained from Fluka Company was converted to nano-sized titania with different particle sizes according to the reported procedure. ${ }^{31,33}$ Preyssler acid was prepared as reported in the literature. ${ }^{34}$ IR spectra were recorded on a Brucker 500 Scientific Spectrophotometer from $\mathrm{KBr}$ pellets. ${ }^{1} \mathrm{H}$ and ${ }^{13} \mathrm{C}$ NMR spectra were obtained on a Bruker $300 \mathrm{MHz}$ Avance spectrometer using $d_{6}$ DMSO as solvent. Ultrasonication was performed in a TRANSSONI 660/H ultrasound cleaner with a frequency of $35 \mathrm{KHz}$ and an output power of $70 \mathrm{~W}$.
2.2 Preparation of the nano-titania supported

Preyssler-type heteropolyacid

nano- $\mathrm{TiO}_{2} / \mathrm{H}_{14}\left[\mathrm{NaP}_{5} \mathrm{~W}_{30} \mathrm{O}_{110}\right]$

Nano-titania particles of $15 \mathrm{~nm}$ size $(1.0 \mathrm{~g})$ were added to a solution of Preyssler acid $(4.5 \mathrm{~g})$ in water $(30 \mathrm{~mL})$ and the mixture was stirred at $20^{\circ} \mathrm{C}$ for $24 \mathrm{~h}$. Then, the resulting mixture was centrifuged to separate the resulting solid material which was stirred in fresh water $(30 \mathrm{~mL})$ for $1 \mathrm{~h}$. Finally, the mixture was centrifuged, washed with ethanol and dried in an oven at $100^{\circ} \mathrm{C}$. The Preyssler heteropolyacid content of the resulting catalyst was determined by titration of the combined water filtrate against $0.01 \mathrm{~N}$ aqueous $\mathrm{NaOH}$ solution that was found to be $0.0056 \mathrm{mmol}$ Preyssler acid per $1 \mathrm{~g} 15 \mathrm{~nm}$ titania. $^{32}$

\subsection{General procedure for one-pot synthesis of tetrahydrobenzo[b]pyrans and 1,4-dihydropyrano[2,3-c]pyrazoles}

To a mixture of aldehyde (1 mmol), malononitrile $(1 \mathrm{mmol})$, dimedone $(1 \mathrm{mmol})$ or 3-methyl-1phenylpyrazolin-5-one, in absolute ethanol $(5 \mathrm{~mL})$, was added nano-titania supported Preyssler-type heteropolyacid catalyst $(25 \mathrm{mg}$ ) with $0.0056 \mathrm{mmol} / \mathrm{g}$ ratio. The reaction mixture was sonicated at $40^{\circ} \mathrm{C}$ for an appropriate time (see tables 3 and 4). After completion of the reaction as monitored by TLC, the resulting mixture was diluted with methanol $(5 \mathrm{~mL})$ and centrifuged to separate the solid catalyst. The filtrate was evaporated under reduced pressure to leave the solid product which was purified by crystallization from ethanol. Structures of the resulting products were established on the basis of their IR, ${ }^{1} \mathrm{H}$ - and ${ }^{13} \mathrm{C}-\mathrm{NMR}$ spectra and physical properties that were consistent with those reported. ${ }^{5,9,11,17-20,28,35-41}$ 


\subsection{Recycling potential of the catalyst}

In order to study the stability and potential reusability of the catalyst, the reaction mixture was centrifuged after the completion. The separated solid was washed with ethyl acetate $(2 \times 5 \mathrm{~mL})$ and dried under reduced pressure $\left(20^{\circ} \mathrm{C}\right)$. The recovered catalyst was reused for three consecutive fresh runs without any significant loss of activity (see tables 3 and 4, entry 1).

\section{Results and discussion}

\subsection{Effect of the titania particle size}

In the present study, various particle sizes of titania were prepared via sol-gel method according to the reported procedure. ${ }^{31,33}$ The resulted particle size distribution was estimated to be 15,30 and $50 \mathrm{~nm}$ as determined by transmission electron microscopy (TEM) images. To investigate the effect of minimizing the particle size of the titania on the rate and yield of the titled reactions, initially we studied the reaction between benzaldehyde $(1 \mathrm{mmol})$, malononitrile $(1 \mathrm{mmol})$ and 5,5-dimethylcyclohexan-1,3-dione $(1 \mathrm{mmol})$ in $\mathrm{EtOH}$ $(5 \mathrm{~mL})$ as the model reaction under reflux condition using various sizes of titania $(25 \mathrm{mg})$ as the catalyst, and the results are schematically presented in figure 1 .

As shown in figure 1, comparison of the reaction rates and yields resulted in the presence of various particle sizes of titania indicates that these two factors of the reaction are both improved with decreasing the size of titania nanoparticles. Moreover, no completion of conversion occurs when the reaction is carried out using micro-titania or in the absence of the catalyst.

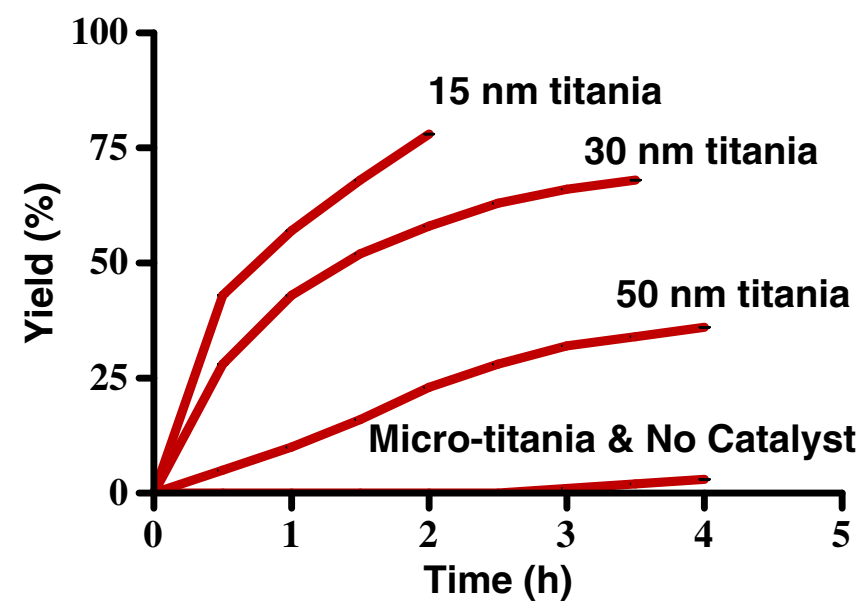

Figure 1. Effect of titania particle size on the rate and yield of the model synthesis of 2-amino-7,7-dimethyl-5-oxo4-phenyl-5,6,7,8-tetrahydro-4H-chromene-3-carbonitrile.
These results are consistent with the BET-specific surface areas of titania of different particle sizes, and indicate that increasing the surface area of titania as catalyst can cause the improvement of reaction rate and yield as well. The BET results obtained from different particle sizes of nano-titania are shown in table 1.

\subsection{Effect of supporting Preyssler acid on nano-titania}

As previously reported, ${ }^{31,32}$ supporting the homogeneous Preyssler acid on the titania can alter the efficiency of the catalyst to improve the reaction yield. Here, we studied the effect of supporting Preyssler acid on nano-titania of $15 \mathrm{~nm}$ particle size as the favourite particle size. To find the most effective molar ratio of the Preyssler acid/nano-titania, we performed thermodynamic study of the adsorption of Preyssler acid on $15 \mathrm{~nm}$ titania. The amount of the adsorbed Preyssler acid per unit mass of the adsorbent ( $\mathrm{mg} / \mathrm{g}$ ) as defined by $\left(q_{e}\right)$ was calculated using the equation (1), where $C_{o}$ and $C_{e}$ are initial and final concentrations of Preyssler acid, respectively $(\mathrm{mg} / \mathrm{L}=\mathrm{ppm}), V$ is the volume of water as solvent (Lit) and $m$ is the weight of nano-titania as adsorbent $(\mathrm{g}){ }^{32}$

$$
q_{e}=\left(C_{0}-C_{e}\right) V / m .
$$

\subsection{Optimizing the reaction conditions}

To establish the reaction conditions, the effect of molar ratio of the Preyssler acid/nano-titania on the aforementioned model reaction was studied under various conditions using the neat nano-titania as well as nano-titaniasupported Preyssler-type heteropolyacid with different molar ratios (table 2).

The results summarized in table 2 clearly indicate the compelling effect of the Preyssler acid on the yield of the reaction $(95 \%$, entry 8$)$ when supported on nanotitania in comparison with the yield $(72 \%)$ obtained from the neat nano-titania as the catalyst (entry 3 ). In addition, the important role of nano-titania as the catalyst was approved by conducting the reaction under

Table 1. BET results for various $n-\mathrm{TiO}_{2}$ particle sizes.

\begin{tabular}{lc}
\hline$n-\mathrm{TiO}_{2}$ particle size $(\mathrm{nm})$ & Specific surface area $\left(\mathrm{m}^{2} / \mathrm{g}\right)$ \\
\hline 15 & 175 \\
30 & 110 \\
50 & 55 \\
Micro size & 15
\end{tabular}


Table 2. Screening the reaction parameters on the nano-titania-supported Preyssler-type heteropolyacid-catalysed model reaction between benzaldehyde, malononitrile and dimedone $\mathrm{e}^{\mathrm{a}}$.

\begin{tabular}{|c|c|c|c|c|c|}
\hline Entry & Catalyst $(\mathrm{mmol} / \mathrm{g})$ & Condition & Solvent & Time (h) & Yield $(\%)^{\mathrm{b}}$ \\
\hline 1 & No catalyst & Reflux & $\mathrm{EtOH}$ & 2 & 10 \\
\hline 2 & Preyssler acid & Reflux & $\mathrm{EtOH}$ & 2 & 81 \\
\hline 3 & Neat nano-titania & Reflux & $\mathrm{EtOH}$ & 2 & 72 \\
\hline 4 & Preyssler acid/nano-titania (0.0012) & Reflux & $\mathrm{EtOH}$ & 1.5 & 77 \\
\hline 5 & Preyssler acid/nano-titania $(0.0024)$ & Reflux & $\mathrm{EtOH}$ & 1.5 & 81 \\
\hline 6 & Preyssler acid/nano-titania $(0.0041)$ & Reflux & $\mathrm{EtOH}$ & 1.5 & 88 \\
\hline 7 & Preyssler acid/nano-titania $(0.0050)$ & Reflux & $\mathrm{EtOH}$ & 1.5 & 91 \\
\hline 8 & Preyssler acid/nano-titania $(0.0056)$ & Reflux & $\mathrm{EtOH}$ & 1.5 & 95 \\
\hline 9 & Preyssler acid/nano-titania $(0.0061)$ & Reflux & $\mathrm{EtOH}$ & 1.5 & 94 \\
\hline 10 & Preyssler acid/nano-titania $(0.0056)$ & Reflux & $t-\mathrm{BuOH}$ & 1.5 & 48 \\
\hline 11 & Preyssler acid/nano-titania $(0.0056)$ & Reflux & EtOAc & 1.5 & 53 \\
\hline 12 & Preyssler acid/nano-titania $(0.0056)$ & Reflux & $\mathrm{H}_{2} \mathrm{O}$ & 1.5 & 61 \\
\hline 13 & Preyssler acid/nano-titania $(0.0056)$ & Reflux & $\mathrm{EtOH} / \mathrm{H}_{2} \mathrm{O}(1: 1)$ & 1.5 & 68 \\
\hline 14 & Preyssler acid/nano-titania $(0.0056)$ & Reflux & $\mathrm{EtOH} / \mathrm{H}_{2} \mathrm{O}(2: 1)$ & 1.5 & 82 \\
\hline 15 & Preyssler acid/nano-titania $(0.0056)$ & Conventional $\left(25^{\circ} \mathrm{C}\right)$ & $\mathrm{EtOH}$ & 1.5 & 33 \\
\hline 16 & Preyssler acid/nano-titania $(0.0056)$ & Sonication $\left(40^{\circ} \mathrm{C}\right)$ & $\mathrm{EtOH}$ & $20 \mathrm{~min}$ & 98 \\
\hline 17 & Preyssler acid/nano-titania $(0.0056)$ & Sonication $\left(50^{\circ} \mathrm{C}\right)$ & $\mathrm{EtOH}$ & $20 \mathrm{~min}$ & 83 \\
\hline 18 & Preyssler acid/nano-titania $(0.0056)$ & Sonication $\left(60^{\circ} \mathrm{C}\right)$ & $\mathrm{EtOH}$ & $20 \mathrm{~min}$ & 71 \\
\hline
\end{tabular}

${ }^{a}$ Conditions: benzaldehyde $(1 \mathrm{mmol})$, dimedone $(1 \mathrm{mmol})$, malononitrile $(1 \mathrm{mmol})$, solid catalyst $(25 \mathrm{mg})$, solvent $(5 \mathrm{~mL})$

${ }^{\mathrm{b}}$ Isolated yield

the catalyst-free condition and also in the presence of neat Preyssler acid that resulted in low (10\%, entry 1$)$ and medium ( $81 \%$, entry 2 ) yields, respectively (entries 1 and 2). Among the green solvents EtOAc, $t-\mathrm{BuOH}$, $\mathrm{EtOH}, \mathrm{H}_{2} \mathrm{O}$, and the mixed solvent EtOH/ $\mathrm{H}_{2} \mathrm{O}$ examined in this reaction, EtOH was found as the solvent of choice which provided the highest rate and yield. Furthermore, the important role of ultrasound irradiation in the acceleration of these reactions is clearly understood by comparing the reaction times and yields carried out under ultrasound conditions (entry 16) with those obtained under conventional heating under reflux (entry 9).

The best result in terms of the reaction time $(20 \mathrm{~min})$ and yield (98\%) was obtained when the reaction was conducted under ultrasound irradiation condition at $40^{\circ} \mathrm{C}$ using the Preyssler acid/nano- $\mathrm{TiO}_{2}$ catalyst in $0.0056 \mathrm{mmol} / \mathrm{g}$ ratio (entry 16). As seen in table 2 (entries 17 and 18), the reaction yield gradually diminishes with increasing the sonication temperature from $40^{\circ} \mathrm{C}$ to $50^{\circ} \mathrm{C}$ and $60^{\circ} \mathrm{C}$. Seemingly, higher temperatures may cause the increase of side product formation in the presence of acidic catalyst. In fact, ultrasound irradiation at lower temperatures not only reduces the reaction times, but can also prevent the possible occurrence of side reactions such as polymerization, hydrolysis or functional group conversions that may occur at higher temperatures.

In order to develop the scope of these reactions, we conducted the reaction with a series of aromatic aldehydes 1a-n bearing different substituent groups under the determined optimized conditions as indicated in table 2 (entry 16). All the reactions proceeded smoothly to afford the respective products $\mathbf{2 a}-\mathbf{n}$ in quantitative yields as summarized in table 3 .

According to the data in table 3, aromatic aldehydes bearing electron-withdrawing groups generally exhibit higher reactivity in this reaction compared to those bearing electron-releasing groups. In addition, the ortho-substituted aldehydes generally undergo this reaction less readily than the meta- and para-substituted aldehydes (see entries 5-6 and 8-10). Difference in reactivity stems from the highest steric hindrance in ortho-substituted aldehydes that makes the carbonyl site less accessible to nucleophilic additions. To the best of our knowledge, most of the reported methods for the synthesis of the titled products are mainly applicable to the aromatic aldehydes. In contrast, as seen in table 3 , the present method is not only suitable for aromatic aldehydes but can also successfully be applied to 
Table 3. Ultrasound-accelerated synthesis of tetrahydrobenzo[b]pyrans $\mathbf{2 a - k}$ catalysed by nano-titania-supported Preyssler-type heteropolyacid ${ }^{\mathrm{a}}$.

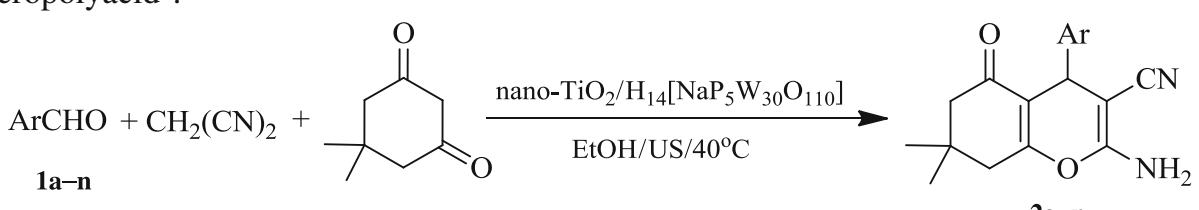
$\mathbf{2 a}-\mathbf{n}$

\begin{tabular}{|c|c|c|c|c|c|c|}
\hline \multirow[b]{2}{*}{ Entry } & \multirow[b]{2}{*}{$\mathrm{Ar}$} & \multirow[b]{2}{*}{ Product 2} & \multirow[b]{2}{*}{ Time (min) } & \multirow[b]{2}{*}{ Yield $(\%)^{\mathrm{b}}$} & \multicolumn{2}{|c|}{ M.p. $\left({ }^{\circ} \mathrm{C}\right)$} \\
\hline & & & & & Found & Reported $^{5,18-20,35-40,42}$ \\
\hline 1 & $\mathrm{C}_{6} \mathrm{H}_{5}$ & $\mathbf{a}$ & 20 & $98,94^{\mathrm{c}}, 93^{\mathrm{d}}, 93^{\mathrm{e}}$ & $226-228$ & $230-232$ \\
\hline 2 & $4-\mathrm{MeOC}_{6} \mathrm{H}_{4}$ & b & 25 & 73 & 198-200 & 194-196 \\
\hline 3 & $4-\mathrm{MeC}_{6} \mathrm{H}_{4}$ & c & 25 & 93 & $210-213$ & $214-216$ \\
\hline 4 & $4-\mathrm{Me}_{2} \mathrm{NC}_{6} \mathrm{H}_{4}$ & d & 40 & 90 & $214-216$ & $217-218$ \\
\hline 5 & $2-\mathrm{ClC}_{6} \mathrm{H}_{4}$ & e & 30 & 86 & $221-223$ & $215-216$ \\
\hline 6 & $4-\mathrm{ClC}_{6} \mathrm{H}_{4}$ & f & 15 & 94 & $222-224$ & $237-239$ \\
\hline 7 & $4-\mathrm{BrC}_{6} \mathrm{H}_{4}$ & g & 30 & 90 & $210-213$ & $201-203$ \\
\hline 8 & $2-\mathrm{NO}_{2} \mathrm{C}_{6} \mathrm{H}_{4}$ & $\mathrm{~h}$ & 30 & 83 & $180-182$ & $182-184$ \\
\hline 9 & $3-\mathrm{NO}_{2} \mathrm{C}_{6} \mathrm{H}_{4}$ & $\mathbf{i}$ & 20 & 98 & $211-213$ & $210-212$ \\
\hline 10 & $4-\mathrm{NO}_{2} \mathrm{C}_{6} \mathrm{H}_{4}$ & $\mathbf{j}$ & 10 & 97 & $151-153$ & $176-178$ \\
\hline 11 & $4-\mathrm{FC}_{6} \mathrm{H}_{4}$ & $\mathbf{k}$ & 10 & 90 & $211-212$ & $211-212$ \\
\hline 12 & $\mathrm{CH}_{3} \mathrm{CH}_{2} \mathrm{CH}_{2}$ & 1 & 30 & 70 & $168-170$ & $172-174$ \\
\hline 13 & Furan-2-yl & $\mathbf{m}$ & 20 & 93 & $228-230$ & $226-228$ \\
\hline 14 & $\mathrm{C}_{6} \mathrm{H}_{5} \mathrm{CH}=\mathrm{CH}$ & $\mathbf{n}$ & 30 & 71 & 195-197 & $182-184$ \\
\hline
\end{tabular}

${ }^{\mathrm{a} C o n d i t i o n s: ~ a l d e h y d e ~}(1 \mathrm{mmol})$, dimedone $(1 \mathrm{mmol})$, malononitrile $(1 \mathrm{mmol})$, solid catalyst $(25 \mathrm{mg})$, EtOH $(5 \mathrm{~mL})$, ultrasound-irradiation condition at $40^{\circ} \mathrm{C}$

${ }^{\mathrm{b}}$ Isolated yields

${ }^{\mathrm{c}, \mathrm{d}, \mathrm{e}}$ Yields of the first, second and third consecutive runs, respectively, for the recycled catalyst

aliphatic, heteroaromatic, and $\alpha, \beta$-unsaturated aldehydes (entries 12-14).

In a putative mechanism suggested for the formation of $4 H$-chromenes as shown in scheme 2, the intermediate (I) is produced upon initial condensation of aldehyde with malononitrile under the catalytic activity of nano-titania-supported Preyssler-type he- teropolyacid. Subsequent nucleophilic addition of dimedone to the intermediate (I) followed successively by intramolecular cyclization to the intermediate (II), and rearrangement to furnish the 2-amino-5-oxo-5,6,7,8tetrahydro- $4 H$-chromenes. A similar mechanism may occur for the formation of $4 H$-pyrano[2,3-c]pyrazole derivatives.
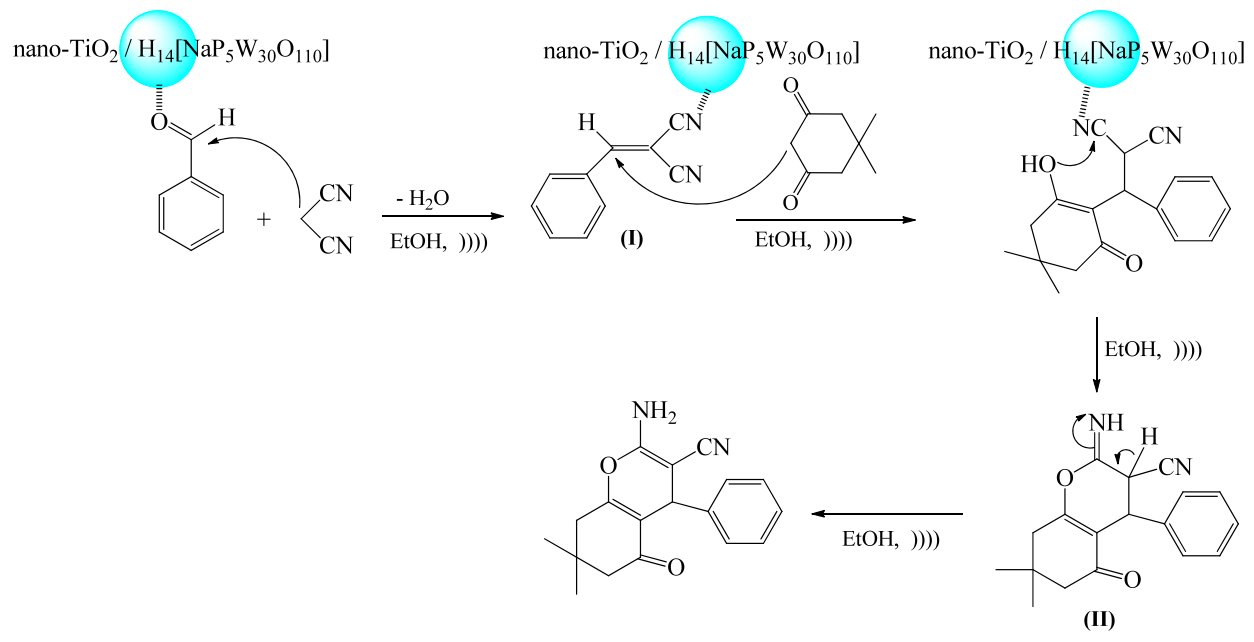

Scheme 2. Possible mechanism for the formation of 2-amino-5-oxo-5,6,7,8-tetrahydro-4H-chromenes. 
Table 4. Ultrasound-accelerated synthesis of dihydropyrano[2,3-c]pyrazoles 3a-m catalysed by nano-titania-supported Preyssler-type heteropolyacid ${ }^{\mathrm{a}}$.

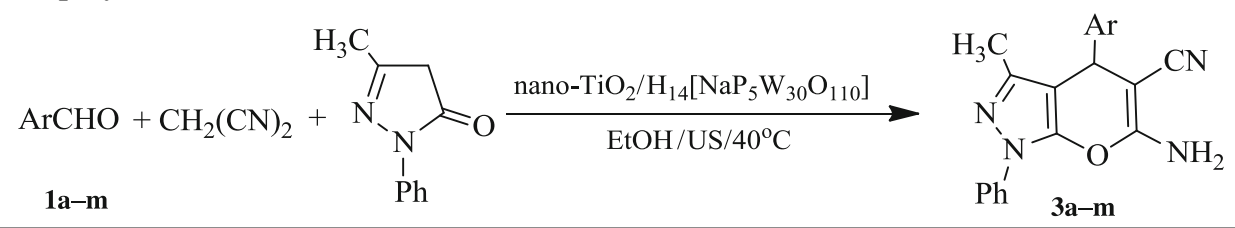

\begin{tabular}{|c|c|c|c|c|c|c|}
\hline \multirow[b]{2}{*}{ Entry } & \multirow[b]{2}{*}{$\mathrm{Ar}$} & \multirow[b]{2}{*}{ Product 3} & \multirow[b]{2}{*}{ Time (min) } & \multirow[b]{2}{*}{ Yield $(\%)^{\mathrm{b}}$} & \multicolumn{2}{|c|}{ M.p. $\left({ }^{\circ} \mathrm{C}\right)$} \\
\hline & & & & & Found & Reported $^{17,28,36}$ \\
\hline 1 & $\mathrm{C}_{6} \mathrm{H}_{5}$ & $\mathbf{a}$ & 15 & $97,95^{\mathrm{c}}, 93^{\mathrm{d}}, 93^{\mathrm{e}}$ & $169-171$ & $167-171$ \\
\hline 2 & $4-\mathrm{MeOC}_{6} \mathrm{H}_{4}$ & b & 30 & 83 & $158-160$ & $169-170$ \\
\hline 3 & $4-\mathrm{MeC}_{6} \mathrm{H}_{4}$ & c & 20 & 93 & $170-171$ & $177-179$ \\
\hline 4 & $2-\mathrm{ClC}_{6} \mathrm{H}_{4}$ & d & 30 & 86 & $140-142$ & $145-146$ \\
\hline 5 & $3-\mathrm{ClC}_{6} \mathrm{H}_{4}$ & e & 15 & 91 & $158-161$ & $158-160$ \\
\hline 6 & $4-\mathrm{ClC}_{6} \mathrm{H}_{4}$ & f & 15 & 95 & $175-178$ & $174-177$ \\
\hline 7 & $4-\mathrm{BrC}_{6} \mathrm{H}_{4}$ & g & 20 & 90 & $187-189$ & $184-185$ \\
\hline 8 & 4- $\mathrm{PhC}_{6} \mathrm{H}_{4}$ & h & 15 & 90 & 191 & $191-193$ \\
\hline 9 & $4-\mathrm{CHOC}_{6} \mathrm{H}_{4}$ & $\mathbf{i}$ & 10 & 83 & 234 & $234-236$ \\
\hline 10 & $3-\mathrm{NO}_{2} \mathrm{C}_{6} \mathrm{H}_{4}$ & $\mathbf{j}$ & 10 & 98 & 189-191 & $190-192$ \\
\hline 11 & $4-\mathrm{NO}_{2} \mathrm{C}_{6} \mathrm{H}_{4}$ & $\mathbf{k}$ & 10 & 97 & 197-198 & 195-197 \\
\hline 12 & $4-\mathrm{FC}_{6} \mathrm{H}_{4}$ & I & 10 & 90 & $170-172$ & $168-169$ \\
\hline 13 & 2-Naphthyl & $\mathbf{m}$ & 12 & 92 & $178-180$ & $176-177$ \\
\hline
\end{tabular}

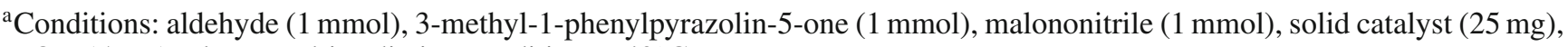
EtOH $(5 \mathrm{~mL})$, ultrasound-irradiation condition at $40^{\circ} \mathrm{C}$

${ }^{\mathrm{b}}$ Isolated yields

c,d,e Yields of the first, second and third consecutive runs, respectively, for the recycled catalyst

These interesting results have encouraged us to extend the scope and generality of the successful application of nano-titania-supported Preysslertype heteropolyacid catalyst to the synthesis of dihydropyrano[2,3-c]pyrazoles $\mathbf{3 a -} \mathbf{m}$ by one-pot reaction between 3-methyl-1-phenylpyrazolin-5-one, aromatic aldehydes and malononitrile under optimized condition (table 2, entry 16); the results are summarized in table 4. As shown in this table, these reactions take place smoothly to furnish the respective products in high to excellent yields. In a similar manner observed for the previous reactions, the rates of these reactions are also governed by steric hindrance around the carbonyl group in the reacting aldehyde.

\section{Conclusion}

In conclusion, we have developed a novel and highly efficient protocol for ultrasound-accelerated one-pot synthesis of tetrahydrobenzo[b]pyrans called chromenes, and 1,4-dihydropyrano[2,3-c]pyrazole derivatives in the presence of nano-titania-supported Preyssler-type heteropolyacid as a heterogeneous catalyst. The reactions proceed smoothly to afford the corresponding products in quantitative yields at short reaction times. The catalyst can be easily recovered and reused for several successive fresh runs with no significant loss of catalytic activity.

\section{Acknowledgements}

The authors wish to thank the Research Council of Bu-Ali Sina University and also the Ministry of Science, Research and Technology of Islamic Republic of Iran for financial support to carry out this research.

\section{References}

1. Zhu J and Bienayme' H 2005 Multicomponent reactions, Weinheim: Wiley-VCH

2. Hall N 1994 Science 26632

3. Domling A and Ugi I 2000 Angew. Chem. Int. Ed. 39 3169

4. Bonsignore L, Loy G, Secci D and Calignano A 1993 Eur. J. Med. Chem. 28517

5. Khaksar S, Rouhollahpour A and Talesh S M 2012 J. Fluorine Chem. 14111

6. Peng Y and Song G 2007 Catal. Commun. 8111

7. Jin T-S, Liu L-B, Zhao Y and Li T-S 2005 Synth. Сотmun. 351859

8. Seshu B N, Pasha N, Venkateswara R K T, Sai P P S and Lingaiah N 2008 Tetrahedron Lett. 492730

9. Banerjee S, Horn A, Khatri H and Sereda G 2011 Tetrahedron Lett. 521878 
10. Kaupp G, Naimi-Jamal M R and Schmeyers J 2003 Tetrahedron $\mathbf{5 9} 3753$

11. Fotouhi L, Heravi M M, Fatehi A and Bakhtiari K 2007 Tetrahedron Lett. 485379

12. Kuo S C, Huang L J and Nakamura H $1984 \mathrm{~J}$. Med. Chem. 27539

13. Wang J-L, Liu D, Zhang Z-J, Shan S, Han X, Srinivasula S M, Croce C M, Alnemri E S and Huang Z 2000 Proc. Natl. Acad. Sci. USA 977124

14. Zaki M E A, Soliman H A, Hiekal O A and Rashad A E 2006 Z. Naturforsch. C 611

15. Balaskar R S, Gavade S N, Mane M S, Shingate B B, Shingare M S and Mane D V 2010 Chinese Chem. Lett. 211175

16. Mecadon H, Rohman M R, Kharbangar I, Laloo B M, Kharkongor I, Rajbangshi M and Myrboh B 2011 Tetrahedron Lett. $\mathbf{5 2} 3228$

17. Heravi M M, Ghods A, Derikvand F, Bakhtiari K and Bamoharram F F 2010 J. Iran Chem. Soc. 7615

18. Vasuki G and Kumaravel K 2008 Tetrahedron Lett. 49 5636

19. Gogoi S and Zhao C-G 2009 Tetrahedron Lett. 502252

20. Sheibani H and Babaie M 2010 Synth. Commun. 40257

21. Azarifar D, Nejat-Yami R, Sameri F and Akrami Z 2012 Lett. Org. Chem. 9435

22. Azarifar D and Sheikh D 2012 Helv. Chim. Acta 951217

23. Azarifar D and Sheikh D 2011 Chem. Het. Comp. 47 1128

24. Teimouri A and Chermahini A N 2011 J. Mol. Catal. A: Chem. 34639

25. Itoh H, Utamapanya S, Stark J V, Klabunde K J and Schlup J R 1993 Chem. Mater. 571
26. Guzman J and Gates B C 2001 Nano Lett. 1689

27. Choudary B M, Kantam M L, Ranganath K V S, Mahendar K and Sreedhar B 2004 J. Am. Chem. Soc. 1263396

28. Azarifar A, Nejat-Yami R, Al-Kobaisi M and Azarifar D 2013 J. Iran Chem. Soc. 10439

29. Bamoharram F F, Heravi M M and Omidinia R 2010 Asian J. Chem. 245582

30. Heravi M M, Bamoharram F F, Rajabzadeh G, Seifi N and Khatami M 2006 J. Mol. Catal. A: Chem. 259213

31. Rahimizadeh M, Rajabzadeh G, Khatami S-M, Eshghi $\mathrm{H}$ and Shiri A 2010 J. Mol. Catal. A: Chem. 32359

32. Azarifar D, Khatami S-M, Zolfigol M A and Sheikh D 2013 J. Iran Chem. Soc. 101039

33. Rajabzadeh G and Jalalian A 2007 Proceedings of the 14th International Sol-gel Conference, Montpellier, France

34. Alizadeh M H, Harmalker S P, Jeannin Y, Martin-Frere J and Pope M T 1985 J. Am. Chem. Soc. 1072662

35. Peng Y, Song G and Dou R 2006 Green Chem. 8573

36. Gao Y, Tu S, Li T, Zhang X, Zhu S, Fang F and Shi D 2004 Synth. Commun. 341295

37. Yu J and Wang H 2005 Synth. Commun. 353133

38. Gao S, Tsai C H, Tseng C and Yao C-F 2008 Tetrahedron 649143

39. Wang L-M, Shao J-H, Tian H, Wang Y-H and Liu B 2006 J. Fluorine Chem. 12797

40. Jin T S, Zhao R Q and Li T S 2006 Arkivoc xiv 176

41. Mohammadi-Ziarani G, Abbasi A, Badiei A and Aslani Z 2011 E-J. Chem. 8293

42. Vasyun'kina T N, Bykova L M, Plotkin V N and Ramsh S M 2005 Russ. J. Org. Chem. 41742 